\title{
Drug importation into Italy by body packing: An analysis of the UNODC Individual Drug Seizures Database
}

Medico-Legal Journa 0 (0) $1-5$

(C) The Author(s) 2018

Reprints and permissions: sagepub.co.uk/journalsPermissions.nav DOI: I0.II77/00258I72I87690I2 journals.sagepub.com/home/mlj SAGE

\author{
Simone Cappelletti 1,2, Alessandro laria ${ }^{3}$, \\ Francesco Lombardo ${ }^{2}$, Giuseppe Vallone ${ }^{2}$, \\ Pasquale Vitale ${ }^{2}$ and Costantino Ciallella'
}

\begin{abstract}
Internal concealment and transportation of illegal substances by body packing is a major business with very high profits, attracting criminals all over the world. As body packers are rarely arrested, it is difficult to quantify their proportion in the general population and, consequently, identify the countries involved in this kind of drug traffic; as a consequence, the percentage of undetected cases is undoubtedly high. The aim of this study is to provide useful information concerning the country of origin of body packers travelling to Italy through the analysis of the United Nations Office on Drugs and Crime Individual Drug Seizures Report database in the period 2010-2015. Results of our study highlighted a total of 85 cases, producing a total of $52.4 \mathrm{~kg}$ of drugs transported through body packing towards Italy. Data obtained from our analysis could represent an useful starting point to: (a) enhance police controls on people coming from targeted countries and improve collaborations between Italian Police Forces and those of other countries; (b) understand the reason why some cities/airports are so frequently used in drug trafficking through body packing and, as a consequence, enhance police controls in these places; and (c) train airport security staffs in international airports recognized as important departure points for body packers travelling to Italy.
\end{abstract}

\section{Keywords}

Body packing, body packers, drug trafficking, cocaine traffic, heroin traffic, drug traffic

\section{Introduction}

Internal concealment and transportation of illegal substances by body packing is a major business with very high profits, attracting criminals all over the world. Body packing is a well-known method of international drug trafficking and Europe represents the fastest growing market for cocaine and heroin transported in this way. ${ }^{1,2}$ Drugs are trafficked to Europe mainly from South America and North Africa, with the most important routes being via air and sea. ${ }^{3}$

As body packers aka "drug mules" are rarely arrested, it is difficult to quantify their proportion in the general population and, consequently, identify the countries involved in this kind of drug importation; as a consequence, the percentage of undetected cases is undoubtedly high. ${ }^{4}$ Researchers and policy makers have sought to understand the business operations of body packers in order to better design and target police efforts and reduce the harm associated with this illicit market.

Due to its strategic central position in the Mediterranean Sea, its extensive coastline, and its numerous minor airports, Italy is one of the main drug gateways to Europe and an important crossroad for international drug trafficking (especially via body packing). Large drug-trafficking organisations

\footnotetext{
'Legal Medicine Section - SAIMLAL Department, SAPIENZA University of Rome, Rome, Italy

${ }^{2}$ State Police Health Service Department, Ministry of Interior, Rome, Italy ${ }^{3}$ Italian Army Health Service Department, Ministry of Defence, Rome, Italy

Corresponding author:

Simone Cappelletti, SAPIENZA University of Rome, Viale Regina Elena, 336, 00161 Rome, Italy.

Email: simone.cappelletti@uniroma I.it
} 
dominate the drug market and have well-established international links to other trafficking regions, such as South America and Africa. ${ }^{5}$

In order to better understand the magnitude of the problem and to give useful data concerning body packing drug importation into Italy, we analysed the United Nations Office on Drugs and Crime (UNODC) Individual Drug Seizures Report database. The UNODC has thematic programmes on research and trend analysis that permit management of global and regional data collections, provides scientific and forensic services, supports Member States in strengthening their data collection, research and forensics capacity, and regularly updates global statistical data on drug trafficking, drug production and drug use.

\section{Materials and methods}

The present study was carried out analysing the Individual Drug Seizures (IDS) Report database, published by the UNODC using data available for the period 2010-2015. An electronic search of the IDS Report database ${ }^{6}$ was performed by two researchers (SC and ST), limited to seizures of cocaine and heroin that had been internally concealed, directed towards Italy. This study was exempt from institutional review board approval as it did not involve human subjects.

\section{Results}

A total of 85 cases of drugs transported by body packing were identified (56 cocaine body packers, 29 heroin body packers), producing a total of $52.4 \mathrm{~kg}$ of drugs transported (37.3 kg of cocaine and $15.1 \mathrm{~kg}$ of heroin); the data giving countries of origins of the body packers, as well as the cities where the seizures took place, are reported in Figures 1 and 2.

The largest number of cocaine body packers came from Brazil, followed by Spain, Argentina and Nigeria (Figure 1).

A comparison between data included in the IDS database and the results of our research highlight that cocaine transported via body packing from Brazil accounts for only a tiny fraction $(1 \%)$ of cocaine transported from Brazil to Italy.

Cocaine transported by this method from Argentina and Nigeria is respectively responsible for $17 \%$ and $73 \%$ of the total quantity of cocaine transported to Italy from these countries.

As highlighted in Figure 1, a considerable number of body packers originated from Spain, France and Belgium; while these countries are not directly involved in cocaine production they are nonetheless the most important European hub countries responsible for cocaine trafficked to Italy.

By contrast, most heroin body packers came from Pakistan, Tanzania and Kenya (Figure 2).

Comparison between data included in the IDS database and the results of our research demonstrate that heroin transported via body packing from Pakistan accounts for only $4 \%$ of the drug transported from that country to Italy.

African countries act as the main hubs for heroin body packing importation into Italy. Spain's role in heroin traffic into Italy is notable, as body packing accounts for $89 \%$ of all heroin transported from Spain to Italy between 2010 and 2015 .

The relatively low number of body packers identified in the IDS database (85 cases) probably underestimates the reality when these statistics are compared to reports in the national media and in the scientific literature, where news of body packing arrests are more frequent. ${ }^{4}$ The reason for this underestimate may be due to the voluntary basis of data submission to the UNODC database by each country.

\section{Discussion}

The main aim of this study is to address the problem posed by countries involved in cocaine and heroin body packing traffic into Italy.

In Europe, Italy included, the share of the overall public drug-related expenditure devoted to supply reduction policies has been increased. ${ }^{7}$ Nevertheless, Italian public policies to combat the body packing phenomenon are insufficient and feeble. Indeed, even if body packing accounts for only a small proportion of the illegal drugs traffic into Italy, it is important from a public health view. The role of a drugs mule is dangerous for the carrier in addition to the harm caused by the drugs themselves when released into the community. It would be helpful for treating doctors and forensic pathologists if there was raised awareness of these dangers which could prevent some of the serious injuries and deaths which occur frequently as a result of the packages leaking or rupturing or obstructing the gastrointestinal lumen. For these reasons, a better understanding and limiting of the Italian body packing phenomenon is urgently required.

The absence of similar studies in literature and in the Italian National Central Anti-drug Services Department (DCSA) annual reports further justify our research. ${ }^{8}$

Data obtained from this short analysis could provide a useful starting point to:

(a) enhance and increase police controls on people coming from targeted countries and improve 

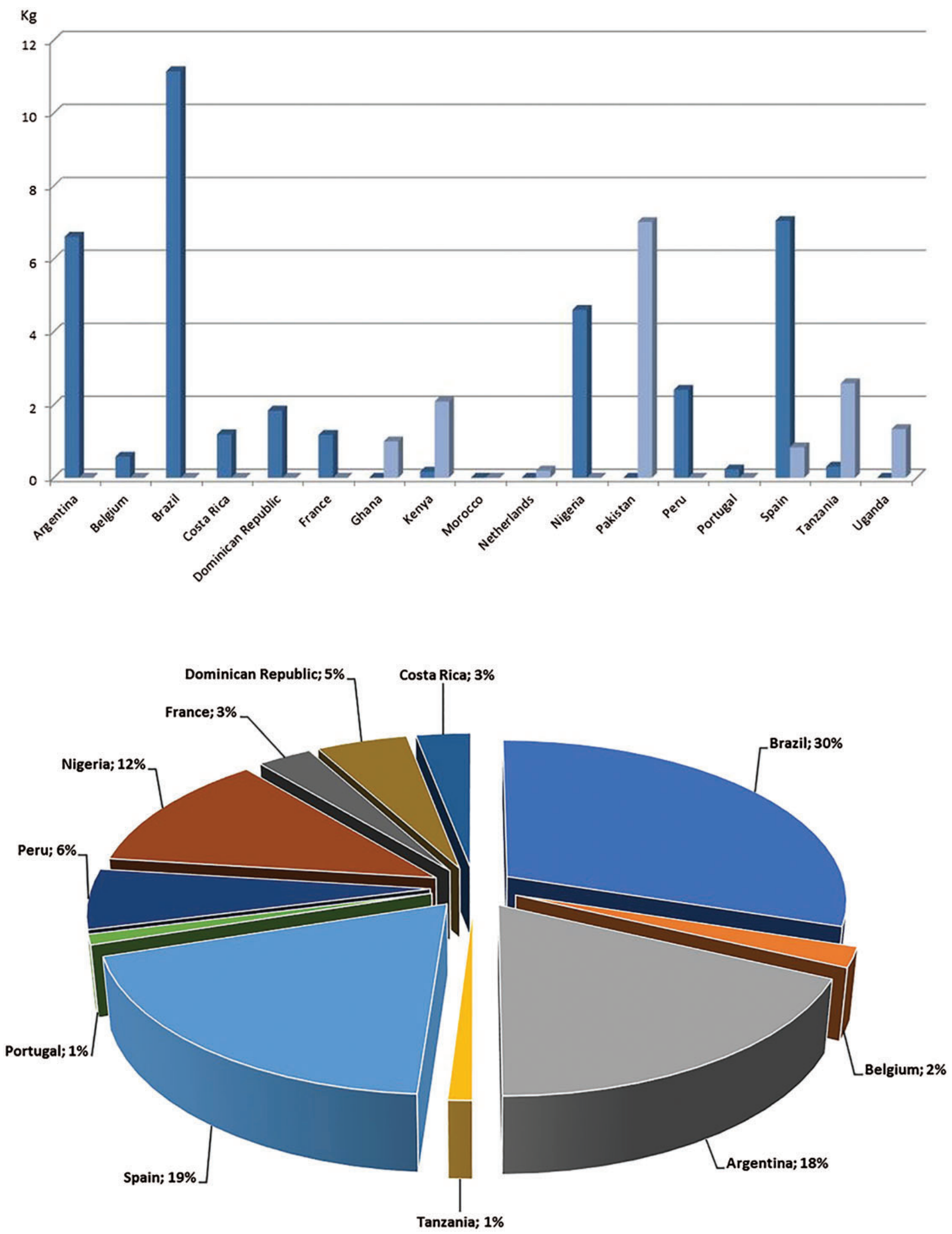

Figure I. Upper graph: Countries of origin involved in cocaine and heroin body packing flows towards Italy for the period 20I02015 by weight of drug seized. Dark blue: cocaine; Light blue: heroin. Note the significance of Brazil and Pakistan for cocaine and heroin drug trafficking through body packing, respectively. Spain is considered an important hub for drug trafficking into Italy. Lower graph: Countries involved in cocaine body packing importations into Italy. 

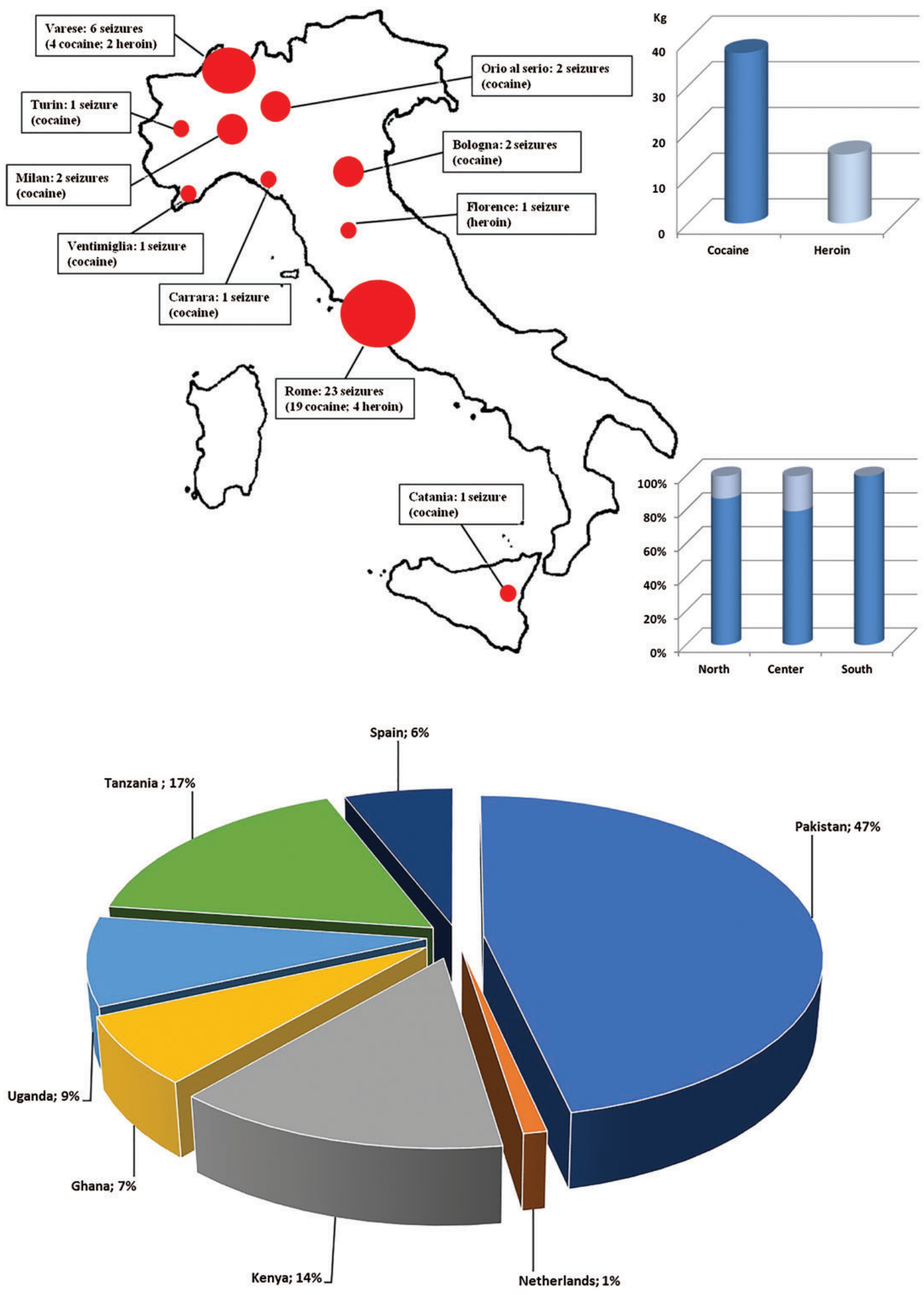

Figure 2. Number of seizures per city where cocaine and heroin body packers were arrested in the period 2010-20I5. The upper right graph represents the amount of cocaine and heroin $(\mathrm{kg})$, transported via body packing. The lower right graph shows the proportion of cocaine and heroin seizures in north, central and south Italy. The lower image shows the countries involved in heroin body packing flows towards Italy. 
collaboration between the Italian Police Forces and those of other countries;

(b) understand the reason why some cities/airports are so frequently used in drug trafficking by body packing and, in consequence, enhance and improve police controls in these places; and

(c) train airport security staff at international airports which are important departure points for body packers travelling to Italy.

\section{Conclusions}

Although the features of body packing have been debated in previous papers, this is the first study aimed at identifying countries of departure for body packers travelling to Italy.

Findings obtained from our study draw attention to the likely underestimation of body packing as a means of transporting illegal drugs as data published appears to represent only the tip of the iceberg. Our results could be integrated with the results obtained from the DCSA annual report in order to give a more comprehensive overview.

Awareness of which countries are involved in drug trafficking via body packing is important as it can assist the police and reduce the quantity of drugs reaching Italy and at the same time avoiding potential health consequences for drug mules. New strategies are urgently needed to fight drug trafficking organisations, predict and prevent its occurrence in the cities which are recognised to be most at risk and reduce the profits earned from illegal drug traffic.

\section{Acknowledgement}

The authors would like to express their appreciation to Dr Silvia Torrini, for her analytical work and for her help with data retrieval.

\section{Declaration of conflicting interests}

The author(s) declared no potential conflicts of interest with respect to the research, authorship, and/or publication of this article.

\section{Funding}

The author(s) received no financial support for the research, authorship, and/or publication of this article.

\section{References}

1. United Nations Office on Drugs and Crime. World Drug Report 2016, www.unodc.org/doc/wdr2016/WORLD_ DRUG_REPORT_2016_web.pdf (accessed 7 February 2018).

2. Traub SJ, Hoffman RS and Nelson LS. Body packing the internal concealment of illicit drugs. New Engl J Med 2003; 349: 2519-2526.

3. Eventon R and Bewley-Taylor D. An overview of recent changes in cocaine trafficking routes into Europe, www.emcdda.europa.eu/system/files/publications/2373/ downloads/EDMR2016\%20Background\%20paper_ Eventon $\% 20$ and $\% 20$ Bewley-Taylor_Cocaine $\% 20$ trafficking\%20to\%20Europe.pdf (accessed 7 February 2018).

4. Cappelletti S, Piacentino D, Sani G, et al. Systematic review of the toxicological and radiological features of body packing. Int J Legal Med 2016; 130: 693-709.

5. Tzvetkova M, Pardal M, Disley E, et al. Strategies for a risky business: how drug dealers manage customers, suppliers and competitors in Italy, Slovenia and Germany. Int J Drug Policy 2016; 31: 90-98.

6. United Nations Office on Drugs and Crime. Individual Drug Seizures Report 2017, https://data.unodc.org (accessed 7 February 2018).

7. Costa Storti $\mathrm{C}$ and De Grauwe P. The cocaine and heroin markets in the era of globalisation and drug reduction policies. Int J Drug Policy 2009; 20: 488-496.

8. National Central Anti-drug Services Department. Annual report 2015, www.interno.gov.it/sites/default/files/allegati/ relazione-annuale-2015.pdf (accessed 7 February 2018). 